\title{
ANALISIS DAN PERANCANGAN APLIKASI BEE-MESSENGER SEBAGAI MEDIA-MEDIA INSTANT MESSANGING DI UNIVERSITAS BINA NUSANTARA
}

\author{
Eddy Santosa Jaya; Irawan; Regan; Indahwati \\ Jurusan Teknik Informatika, Fakultas Ilmu Komputer, Universitas Bina Nusantara \\ Jln K.H. Syahdan No.9 Palmerah Jakarta Barat 11480 \\ eddys@binus.edu
}

\begin{abstract}
Technology today has progressed at a rapid rate, as well as with instant messaging growing into all aspects of life, even more so in the advancement of communication technology. By using the VoIP feature, users can communicate by voice via the Internet. Messenger as a communication medium that is fast, accurate and low cost is expected to meet the need for a practical communication media. The purpose of this study is to analyze and design a messaging application called Bee-Messenger which will be used as a medium of instant messaging in Bina Nusantara University, and also analyze the needs of users with feature-contained in commonly used messenger applications. Research methods used are literature review, field studies, and field observations. Evaluation is based on the comparison of Bee-Messenger features with the same features found in Yahoo Messenger and MSN Messenger. Bee-Messenger can also activate YM and MSN messaging accounts simultaneously in a single application that gives users a practical application messaging.
\end{abstract}

Keywords: feature comparison, VoIP, instant messaging.

\begin{abstract}
ABSTRAK
Saat ini teknologi sudah sangat pesat kemajuannya, begitu juga dengan instant messaging yang semakin berkembang ke segala aspek kehidupan, terlebih lagi dalam kemajuan teknologi komunikasi. Dengan menggunakan fitur VoIP, user dapat berkomunikasi dengan suara melalui media internet. Messenger sebagai salah satu media komunikasi yang cepat, tepat dan low cost diharapkan dapat memenuhi kebutuhan akan sebuah media komunikasi yang praktis. Tujuan dari penelitian ini adalah untuk menganalisa dan merancang aplikasi messaging yang bernama Bee-Messenger yang akan digunakan sebagai media instant messaging di Universitas Bina Nusantara, dan juga menganalisa kebutuhan user akan fitur-fitur yang terdapat dalam aplikasi-aplikasi messenger yang populer. Metode penelitian yang digunakan adalah studi kepustakaan, studi lapangan, dan observasi lapangan. Evaluasi dilakukan berdasarkan hasil perbandingan fitur-fitur BeeMessenger yang sama dengan fitur-fitur yang terdapat dalam Yahoo Messenger dan MSN Messenger. BeeMessenger juga dapat mengaktifkan account messaging YM dan MSN secara bersamaan dalam satu aplikasi sehingga memberikan user sebuah aplikasi messaging yang praktis.
\end{abstract}

Kata kunci: perbandingan fitur, VoIP, instant messaging . 


\section{PENDAHULUAN}

\section{Latar Belakang}

Saat ini teknologi sudah sangat pesat kemajuannya, semakin berkembang ke segala aspek kehidupan, terlebih dalam kemajuan teknologi komunikasi. Perkembangan teknologi yang sudah ada sekarang ini menjadikan persaingan dunia usaha semakin kompetitif dan ketat persaingannya. Banyak perusahaan yang berlomba-lomba memasarkan produk mereka melalui media-media yang sudah tersedia sekarang ini, salah satu media pemasarannya adalah melalui internet. Seperti kita tahu, internet sudah sangat mudah diakses setiap orang, dari berbagai kalangan tak terbatas oleh umur, oleh karena itu teknologi komunikasi sekarang sangat maju dengan adanya internet. Dengan banyaknya orang menggunakan internet berbagai jenis komunitas muncul untuk saling bertukar informasi satu sama lain. Namun, untuk membuat suatu komunitas diperlukan media komunikasi yang dapat berkomunikasi dengan sesama anggota komunitas tersebut. Salah satu metode komunikasi internet yang digunakan dalam komunitas adalah dengan menggunakan instant messaging, seperti contohnya adalah Yahoo Messenger dan Windows Live Messenger.

Instant messaging sudah banyak dipakai oleh banyak orang, tidak luput dari semua kalangan, baik tua maupun muda, karena instant messaging merupakan sarana komunikasi yang cepat, murah dan mudah digunakan. Dalam penggunaan instant messaging sendiri seseorang dapat memiliki lebih dari satu account instant messaging. Untuk memenuhi kebutuhan user itulah, diperlukan sebuah aplikasi yang bisa mendukung beberapa produk instant messaging. Aplikasi tersebut adalah BeeMessenger yang akan penulis kembangkan. User dapat dengan mudah login ke lebih dari satu account instant messaging mereka, dan juga user mendapatkan fasilitas yang lebih dari sekedar instant messaging, di dalam Bee-Messenger ditambahkan beberapa plug-in yang menunjang kenyamanan dalam berkomunikasi, yaitu Voice over Internet Protocol.

\section{Landasan Teori}

\section{XMPP}

XMPP (The Extensible Messanging and Presence Protocol) adalah teknologi yang terbuka untuk komunikasi real-time, kekuasaan yang beragam termasuk aplikasi pesan instan, keberadaan multipihak obrolan, panggilan voice dan video, kolaborasi, middleware ringan, konten sindikasi, routing atas data XML secara umum. (Anonim 9, 1999). XMPP pada awalnya dikembangkan oleh Jabber Open-source community, yang merupakan sebuah komunitas Programmer untuk memberikan suatu layanan piranti lunak yang terbuka, aman, bebas spam, desentralisasi alternatif ke layanan pesan instan yang tertutup pada waktu itu.

\section{Konsep Messaging}

Dalam perkembangan teknologi pada saat ini sering terjadi berbagai macam penemuanpenemuan terbaru dari developers guna mempermudah aktivitas dan kegiatan yang dilakukan oleh manusia. Salah satunya messaging yang merupakan alat komunikasi antara komputer satu dengan komputer lain dengan mengirim pesan (message) kepada komputer yang dituju dengan melalui media internet. Dengan demikian dapat diartikan pula messaging sebagai media komunikasi yang mengandalkan internet sebagai media pengiriman pesan (message). Messaging termasuk berbagai spektrum dari email, pesan yang berupa text yang terdapat pada handphone yang biasa disebut SMS (Short Message Service), instant messaging, sampai dengan Voice-Over-IP (VoIP) merupakan teknologi yang sangat diminati pada saat ini karena kemampuannya yang mampu mengirim pesan secara cepat dan dapat diterima secara langsung setelah beberapa detik dikirim oleh pengirim. Namun 
dalam proses pengiriman pesan yang sebenarnya tidak dilakukan secara mudah karena melibatkan client dan server. Client yang ingin mengirim pesan harus melakukan identifikasi terlebih dahulu agar client dapat dikenali oleh server. Pada saat client ingin mengirim pesan maka client harus memberikan alamat tujuan pengiriman pesan tersebut kepada messaging server sehingga ketika pesan tersebut akan diterima oleh messaging server yang akan mengecek alamat yang dituju dan kemudian dikirimkan ke alamat tersebut. Messaging server merupakan suatu program middleware yang menangani pesan yang akan dikirim menggunakan program yang lain dengan menggunakan suatu aplikasi Messaging. Dalam pengiriman pesan messaging server memiliki dua model yaitu the point-to-point model dan the publish/subscribe model. Pada the point-to-point model digunakan pada saat pengiriman pesan secara langsung melalui instant messaging sedangkan the publish/subscribe model digunakan pada email.

\section{METODE}

Adapun metodologi yang di terapkan dalam menganalisa dan merancang aplikasi BeeMessenger adalah: (1) Studi kepustakaan, penulis mencari informasi yang berasal dari buku-buku dan berbagai bacaan lain yang terkait dengan topik yang sedang di bahas; (2) Studi lapangan, penulis langsung bertanya kepihak yang bersangkutan untuk mendapatkan data yang diinginkan dan penulis memberikan sejumlah pertanyaan tertulis yang digunakan untuk memperoleh informasi dari responden; (3) Analisis sistem, dilakukan tiga tahap yaitu melakukan pengumpulan data menggunakan wawancara pada pihak coorporate; menggunakan beberapa pertanyaan pada pihak yang bersangkutan melalui kuesioner, dan mempelajari sistem messaging yang berjalan di Universitas Bina Nusantara; dan (4) Metode perancangan aplikasi, dengan menggunakan Object Oriented Programming (OOP) melalui pendekatan Unified Modeling Language(UML).

\section{HASIL DAN PEMBAHASAN}

\section{Analisis Sistem Messanging yang Berjalan di Universitas Bina Nusantara}

Melalui wawancara yang dilakukan di Universitas Bina Nusantara dengan salah seorang staff network engineer di bagian Applied Technology Laboratories (ATL), maka didapatkan gambaran mengenai sistem messaging yang berjalan di Universitas Bina Nusantara, yaitu bahwa sebagian besar Binusian (Mahasiswa aktif, alumni, karyawan, semua yang tergabung dalam keluarga besar Universitas Bina Nusantara) menggunakan messenger dari provider-provider yang terkenal seperti YM dan MSN. Media-media instant messanging yang digunakan di Universitas Bina Nusantara pada saat ini, mendukung fitur-fitur seperti Messanging, SMS, Conference, hingga VoIP.

\section{Identifikasi Permasalahan}

Dengan memperhatikan hasil wawancara dan kuesioner, maka berikut adalah rangkuman dari identifikasi permasalahan antara lain perbandingan penggunaan fitur-fitur YM dan MSN yang sering digunakan user. Berdasarkan Tabel 1 dapat diketahui fitur-fitur instant messaging yang sering digunakan oleh user. Dan berdasarkan hal tersebut, maka diperlukan aplikasi instant messaging yang juga mendukung fitur-fitur tersebut seperti YM dan MSN.

Tabel 1. Perbandingan Fitur antara YM dan MSN

\begin{tabular}{lcc}
\hline \multicolumn{1}{c}{ Fitur } & YM & MSN \\
\hline Transfer File & Ya & Ya \\
Conference & Ya & Ya \\
\hline
\end{tabular}




\begin{tabular}{lll}
\hline Offline Messages & Ya & Ya \\
Avatar & Ya & Ya \\
Webcam & Ya & Ya \\
VoIP & Ya & Ya \\
\hline
\end{tabular}

Aplikasi-aplikasi IM yang telah ada seperti YM, MSN, dll tidak dapat dimodifikasi. Sehingga komunitas tersebut tidak dapat menambahkan atau mengurangi fitur-fitur yang ada di messenger tersebut.

Penggunaan beberapa aplikasi IM sekaligus menimbulkan kebutuhan akan sebuah Instant Messenger (IM) yang lebih praktis. User cenderung menyalakan beberapa aplikasi IM secara bersamasama dalam sebuah komputer, hal ini dirasakan sangat tidak praktis.

\section{Deskripsi Alur Proses}

User menjalankan Bee-Messenger, dan melakukan login ke openfire server. Openfire server melakukan autentifikasi user dengan data-data yang telah di-read dari LDAP dan ditampung di dalam database internal yang ada di dalam database openfire. Kemudian apabila berhasil login maka user akan masuk ke halaman utama di mana user dapat mulai menggunakan Bee-Messenger.

User juga dapat mengaktifkan account IM yang lain (yaitu YM dan MSN) dengan memasukkan login information pada bagian yang tersedia di aplikasi Bee-Messenger. Login information yang telah dimasukkan akan dikirim ke server openfire, dan server yang akan melakukan proses login ke YM dan MSN menggunakan IM Gateway. Setiap pesan yang dikirim oleh user kepada user lain dengan account YM atau MSN akan melalui openfire yang akan diproses oleh messaging server diteruskan ke YM atau MSN menggunakan IM Gateway, begitu juga sebaliknya pesan dari YM dan MSN akan melalui IM Gateway dan diproses di messaging server dalam openfire.

Selain itu user dapat melakukan phone call, program client melakukan mapping terlebih dahulu tentang informasi SIP username dan server SIP PBX yang digunakan, dan setelah itu apabila fitur phone call sudah siap digunakan, maka user melakukan phone call melalui server SIP PBX. Karena Bee-Messenger merupakan aplikasi yang dikembangkan dari aplikasi open source, maka aplikasi Bee-Messenger akan dapat dimodifikasi.

\section{Arsitektur Sistem}

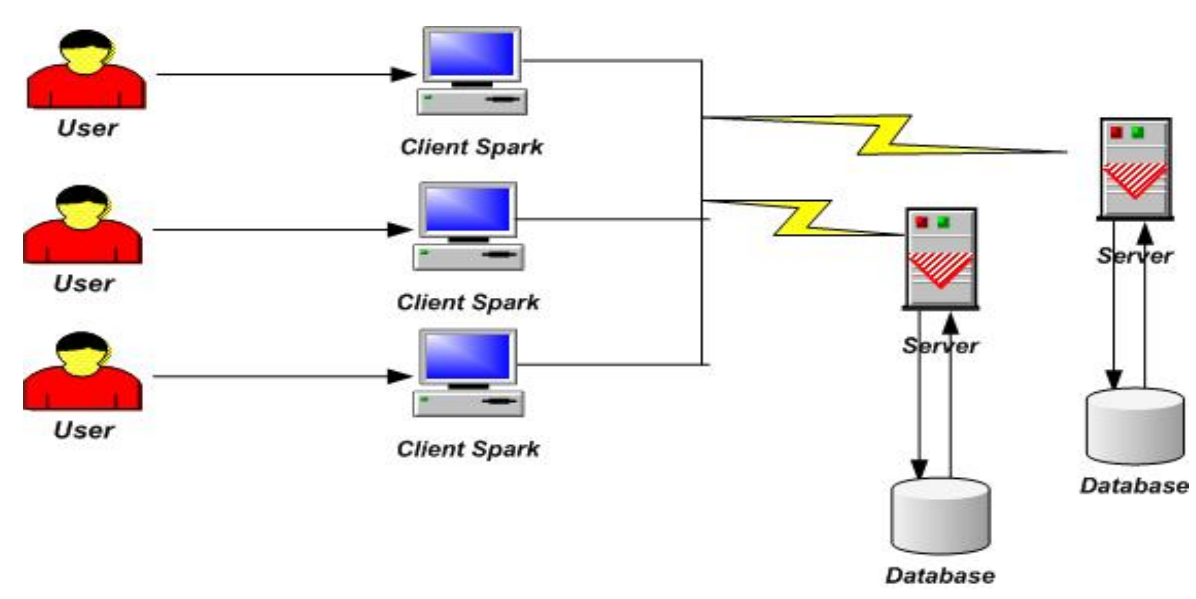

Gambar 1 Arsitektur Spark 
User menginstal spark dalam komputer kemudian user melakukan login menggunakan internet. Server yang digunakan spark ditentukan sendiri oleh user. Arsitektur sistem yang menggunakan Spark terlihat pada Gambar 1.

\section{Arsitektur Bee-Messenger}

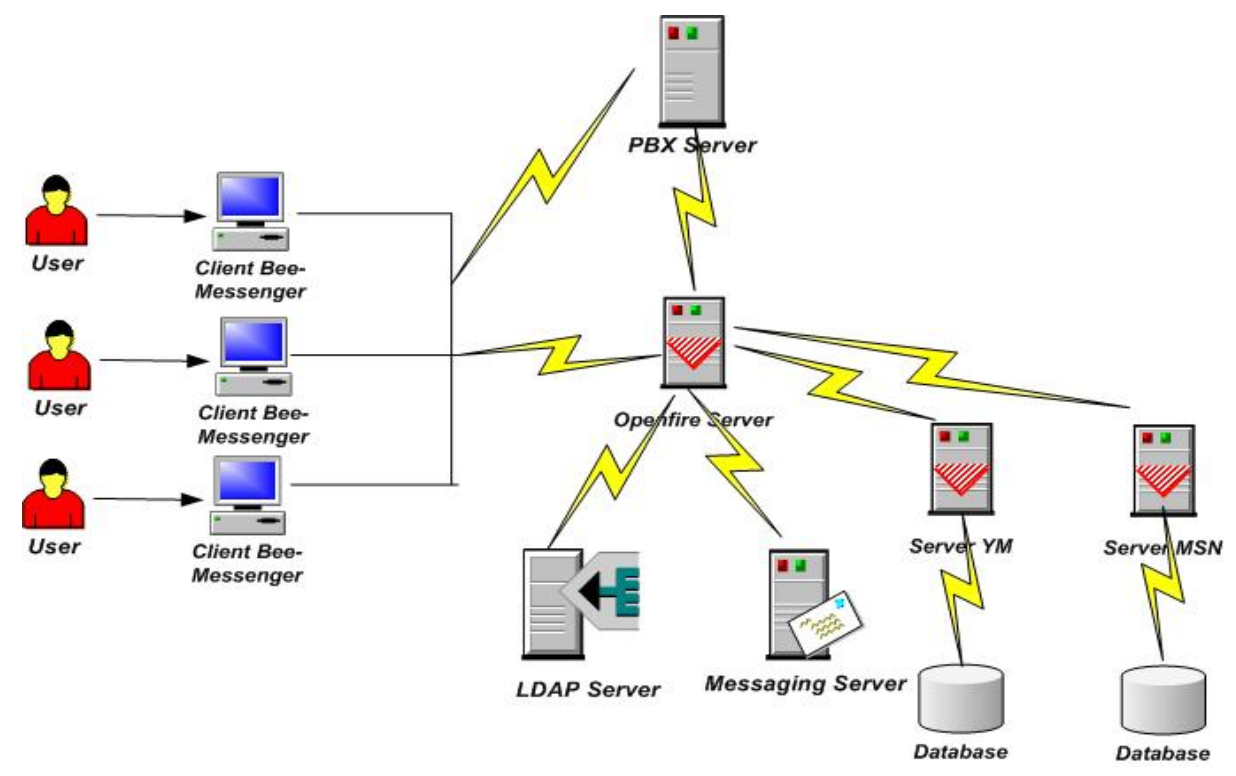

Gambar 2 Arsitektur Bee-Messenger

Gambar 2 menunjukkan arsitektur sistem untuk Bee-Messenger. User melakukan chat melalui openfire server maka akan dikoneksikan dengan LDAP server apabila sudah terdaftar sebagai user maka akan dikembalikan ke openfire server dan dihubungkan dengan messaging server dan user dapat berkomunikasi chat. Untuk phone PC-ke-PC user akan dikoneksikan PBX server melalui openfire server namun ketika koneksi tersambung maka user akan langsung melalui PBX server. Untuk koneksi YM dan MSN kan disambungkan oleh openfire server dan dikoneksikan ke user.

\section{Arsitektur Server}

User menginstal Bee-Messenger lalu login melalui internet. Server yang digunakan adalah openfire yang di integrasi LDAP (lihat Gambar 3). Apabila user menggunakan YM dan MSN bersama di Bee-Messenger.

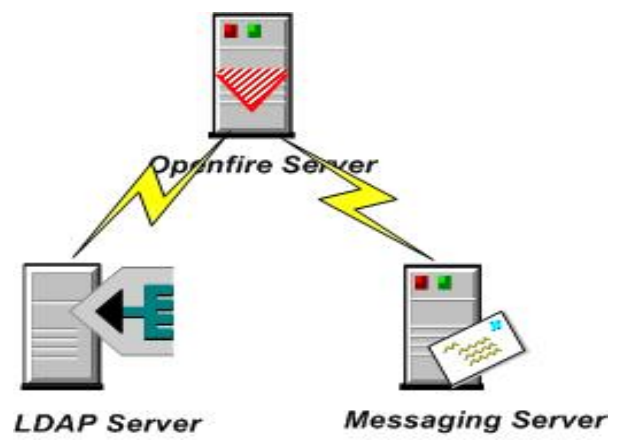

Gambar 3 Arsitektur Server 


\section{Arsitektur Openfire}

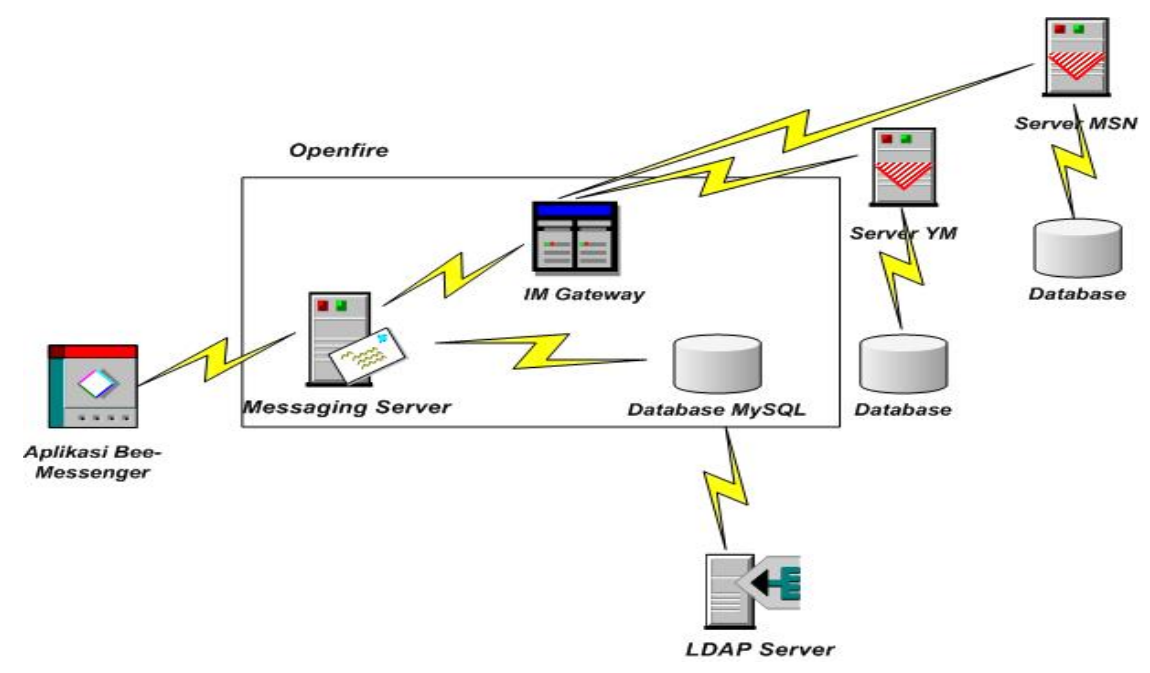

Gambar 4 Arsitektur Openfire

Gambar 4 di atas merupakan proses yang terjadi di dalam openfire server pada saat melakukan koneksi server YM dan server MSN. Dalam koneksi dengan YM dan MSN, messaging server akan mengkoneksikan dengan plugin IM-gateway yang ada openfire dan melalui plugin tersebut dapat terkoneksi server YM dan server MSN.

\section{Implementasi Sistem}

Dalam penerapan sistem Bee-Messenger ini, ada 2 komponen utama yang menjadi pendukung sistem ini, yaitu komponen perangkat keras dan perangkat lunak.

\section{Kebutuhan Sumber Daya Manusia (SDM)}

Pada komputer server, dibutuhkan sumber daya yang mengerti mengenai network dan database, sehingga bisa disimpulkan bahwa komputer server membutuhkan network administrator dan console administrator untuk mengatur administration console yang terdapat pada openfire.

Pada komputer client, aplikasi dapat dipakai oleh siapa saja dengan sedikit pengetahuan dalam penggunaan komputer.

\section{Evaluasi Wawancara}

Untuk mendukung data-data yang ada, maka penulis melakukan wawancara kepada beberapa Universitas Bina Nusantaraian yang telah menggunakan Bee-Messenger. Daftar pertanyaan dapat dilihat pada Tabel 2. Tempat wawancara dilakukan secara online melalui media komunikasi online yakni Bee-Messenger. Pada jam 8 malam.

Tabel 2 Pertanyaan Wawancara Untuk User.

\begin{tabular}{ll}
\hline No & Pertanyaan \\
\hline 1 & Bagaimanakah kecepatan request response Bee-Messenger? \\
\hline 2 & Apakah fitur-fitur Bee-Messenger sudah dapat men-cover fitur-fitur yang ada pada YM dan MSN? \\
\hline 3 & Apakah Bee-Messenger sudah dapat memenuhi kebutuhan user akan sebuah messenger yang praktis? \\
\hline
\end{tabular}




\begin{tabular}{ll}
\hline 4 & Apakah anda mendapat kesulitan dalam menavigasikan Bee-Messenger? \\
\hline 5 & Apakah user interface Bee-Messenger menarik? \\
\hline 6 & Bagaimana kualitas suara yang dihasilkan Bee-Messenger dalam fitur VoIP? \\
\hline
\end{tabular}

Dari pertanyaan-pertanyaan yang diberikan kepada para Binusian secara langsung, maka didapatkan hasil yang telah dikompilasi pada Tabel 3.

Tabel 3. Kompilasi Jawaban Wawancara User

\begin{tabular}{ll}
\hline No & Pertanyaan \\
\hline 1 & Kecepatan request response Bee-Messenger sangat cepat. \\
\hline 2 & $\begin{array}{l}\text { Fitur-fitur standar Bee-Messenger dirasakan sudah dapat men-cover standar fitur-fitur yang ada } \\
\text { pada messenger lainnya. }\end{array}$ \\
\hline 3 & Bee-Messenger sudah dapat memenuhi kebutuhan user akan sebuah messenger yang praktis. \\
\hline 4 & Sebagian besar user mengatakan bahwa Bee-Messenger sangat mudah untuk dinavigasikan. \\
\hline 5 & User interface Bee-Messenger dirasakan kurang menarik. \\
\hline 6 & Suara VoIP yang dihasilkan akan sangat bergantung sekali kepada koneksi internet user. \\
\hline 7 & $\begin{array}{l}\text { Plugin-plugin yang ada di Bee-Messenger lebih banyak dibandingkan dengan messenger } \\
\text { messenger lainnya. }\end{array}$ \\
\hline
\end{tabular}

\section{Evaluasi Client}

Beberapa hal yang diamati dari penggunaan Bee-Messenger dengan messenger lain seperti YM dan MSN pada komputer client adalah penggunaan space harddisk dan penggunaan memory (lihat Tabel 4).

Tabel 4. Perbandingan Ruang Harddisk dan Memory yang Digunakan

\begin{tabular}{cccc}
\hline & YM & MSN & $\begin{array}{c}\text { Bee-Messenger } \\
\text { (Dengan JRE) }\end{array}$ \\
\hline Size & $46.9 \mathrm{MB}$ & $40.5 \mathrm{MB}$ & $81.5 \mathrm{MB}$ \\
\hline Size on Disk & $55.0 \mathrm{MB}$ & $40.6 \mathrm{MB}$ & $83.4 \mathrm{MB}$ \\
\hline Penggunaan Memory & $48.644 \mathrm{~K}$ & $26.900 \mathrm{~K}$ & $31.108 \mathrm{~K}$ \\
\hline
\end{tabular}

\section{Evaluasi Fitur}

Tabel 5 berikut merupakan Evaluasi Fitur antara Bee-Messenger, dengan YM dengan MSN.

Tabel 5. Perbandingan Fitur antara YM, MSN dan Bee-Messenger

\begin{tabular}{|c|c|c|c|}
\hline Fitur & YM & MSN & Bee-messenger \\
\hline Conference & $\mathrm{Ya}$ & $\mathrm{Ya}$ & $\mathrm{Ya}$ \\
\hline VoIP & $\mathrm{Ya}$ & $\mathrm{Ya}$ & $\mathrm{Ya}$ \\
\hline Webcam & $\mathrm{Ya}$ & $\mathrm{Ya}$ & Tidak \\
\hline IM dengan teman yang menggunakan IM lainnya & $\mathrm{Ya}$ & $\mathrm{Ya}$ & $\mathrm{Ya}$ \\
\hline Transfer File & $\mathrm{Ya}$ & $\mathrm{Ya}$ & $\mathrm{Ya}$ \\
\hline SMS & $\mathrm{Ya}$ & $\mathrm{Ya}$ & Tidak \\
\hline Search Panel & $\mathrm{Ya}$ & $\mathrm{Ya}$ & $\mathrm{Ya}$ \\
\hline Notification email & Ya & $\mathrm{Ya}$ & $\mathrm{Ya}$ \\
\hline Pengarsipan Pesan & Ya & Ya & $\mathrm{Ya}$ \\
\hline Updates & $\mathrm{Ya}$ & $\mathrm{Ya}$ & $\mathrm{Ya}$ \\
\hline Emoticon & $\mathrm{Ya}$ & $\mathrm{Ya}$ & $\mathrm{Ya}$ \\
\hline Avatar & $\mathrm{Ya}$ & $\mathrm{Ya}$ & $\mathrm{Ya}$ \\
\hline
\end{tabular}




\begin{tabular}{lccc}
\hline Picture Display & Ya & Ya & Ya \\
\hline Games & Ya & Ya & Tidak \\
\hline Pesan status buatan sendiri & Ya & Ya & Ya \\
\hline Huruf dan warna yang bisa dimodifikasi & Ya & Ya & Ya \\
\hline Tambah emoticon & Tidak & Ya & Ya \\
\hline Set status(busy,away,dll) & Ya & Ya & Ya \\
\hline Buku Alamat & Ya & Ya & Ya \\
\hline Pesan Online & Ya & Ya & Ya \\
\hline Broadcast & Tidak & Tidak & Ya \\
\hline Spelling Check & Tidak & Tidak & Ya \\
\hline Notes & Tidak & Tidak & Ya \\
\hline Alert user ketika user available & Ya & Ya & Ya \\
\hline Alert notification to user & Ya & Ya & Ya \\
\hline Add Plugins & Ya & Tidak & Ya \\
\hline
\end{tabular}

Berdasarkan tabel 5 dapat diketahui perbandingan fitur-fitur yang didukung dan yang tidak didukung oleh Bee-Messenger dengan YM dan MSN. Bee-Messenger belum mempunyai fitur Webcam, SMS, Games. Bee-Messenger sudah mendukung fitur-fitur yang sering digunakan oleh user yaitu, Transfer File, Conference, Offline Messages, Avatar, VoIP dan dari hasil wawancara terhadap user (Tabel 3) yang menggunakan Bee-Messenger, bahwa fitur-fitur yang sudah dimiliki oleh BeeMessenger sudah dapat men-cover fitur-fitur yang ada pada sebuah messenger.

\section{PENUTUP}

\section{Simpulan}

Beberapa kesimpulan yang didapat dari penelitian ini, ialah: (1) Implementasi Bee-Messenger sangat membantu user dalam memenuhi kebutuhan aplikasi yang praktis karena dapat mengaktifkan account YM, MSN dan Bee-Messenger secara bersamaan; (2) Bee-Messenger dirancang untuk memenuhi kebutuhan sebuah komunitas yang membutuhkan sebuah messenger sebagai media komunikasinya; (3) Bee-Messenger dapat dimodifikasi sesuai kebutuhan, salah satunya yang dimodifikasi adalah client Bee-Messenger tidak lagi melakukan pemilihan server tetapi langsung mengacu pada server messenger yang telah disediakan; dan (4) Dari hasil evaluasi fitur-fitur BeeMessenger dengan messenger yang lain, fitur Bee-Messenger sudah dapat meng-cover fitur-fitur yang sering digunakan user dalam sebuah messenger, hal tersebut dapat diketahui dari perbandingan fitur antara Bee-Messenger dengan YM dan MSN.

\section{Saran}

Beberapa saran untuk pengembangan lebih lanjut, antara lain: (1) user interface yang ada harus di-design agar tampak lebih menarik dan user friendly; (2) User disarankan untuk menggunakan spesifikasi komputer yang sesuai dengan system requirement yang sudah dibahas pada bab sebelumnya, agar sistem dapat berjalan sesuai dengan yang diharapkan; dan (3) dikarenakan fitur-fitur yang terdapat pada Bee-Messenger ditujukan agar dapat men-cover fitur-fitur yang sering digunakan oleh user terlebih dahulu, maka dibutuhkan penelitian lebih lanjut terhadap pengembangan fitur-fitur Bee-Messenger sehingga lebih variatif dan menarik. 


\section{DAFTAR PUSTAKA}

Black,U. (2000). Voice Over IP. New Jersey: Prentice Hall.

Goncalves, M. (1999). Voice Over IP Networks. New York: McGraw-Hill.

Hunt, C. (2002). TCP/IP Network Administration, Third Edition. Canada: O'Reilly \& Associates, Inc.

Lammle,T. (2004). CCNA Cisco Certified Network Associate Study Guide. California: Sybex.

Tanenbaum, A. (2003). Computer Networks, $4^{\text {th }}$ edition. New Jersey: Prentice Hall.

Turban, E., Rainer, R.K., \& Potter, R.E. (2003). Introduction to Information Technology, $2^{\text {nd }}$ Edition. New Jersey: John Wiley \& Sons, Inc. 